\title{
APROKSIMASI NUMERIK BELAH DUA DAN NEWTON-RAPHSON PADA ESTIMASI PARAMETER DISTRIBUSI WEIBULL
}

\author{
Indira P. Kinasih \\ Jurusan Pendidikan Matematika IKIP Mataram \\ e-mail : indiraputeri@gmail.com
}

\begin{abstract}
ABSTRAK
Distribusi masa aktif produk bergaransi, misalkan kendaraan bermotor dan mesin fotokopi merupakan hal yang menarik untuk dipelajari. Faktanya, distribusi kerusakan atau masa hidup produk bergaransi seringkali memiliki plot fungsi kepadatan peluang yang condong ke kanan. Terkait hal ini, distribusi Weibull termasuk salah satu ragam distribusi non-negatif yang biasanya sesuai untuk memodelkan distribusi data. Karena fungsi distribusi kerusakan merupakan fungsi dari parameter, maka estimasi parameter selalu menjadi kebutuhan utama pada masalah pemodelan distribusi kerusakan. Ketiadaan solusi analitis pada maksimasi fungsi persekitaran distribusi Weibull mengakibatkan pendekatan numerik menjadi solusi pilihan. Dua macam metode numerik, yaitu Newton-Raphson dan belah dua disajikan pada makalah ini untuk diamati perbandingan kecepatan dan keakuratan keduanya dalam pencarian solusi. Data yang digunakan adalah data kerusakan mesin fotokopi berdasarkan usia dan banyak salinan yang terekam pada saat kerusakan selama 4,5 tahun, bersumber dari penelitian Bulmer dan Eccleston [1].
\end{abstract}

Kata kunci : Distribusi Weibull, Newton-Raphson, belah dua, parameter , fungsi persekitaran

\section{ABSTRACT}

Life time distribution of warranted product, for example like automobile and photocopier is an interesting studies. Based on the fact that mostly, life distribution of warranted product is somewhat skewed to the right, this suggests that usual failure distribution such as Weibull distribution may provide a reasonable fit to the data. Related to these studies, parameter estimation is directly applicable since life distribution function is a function of parameters. There are no closed solution for Weibull likelihood function maximation. Therefore, numerical approximation could be an alternative solution. In this paper, Newton-Raphson and bisection method were employed to estimate the scale and shape parameter of Weibull distribution for photocopier failure data for since 4,5 years. Performance of those method were compared based on their approximation result and how fast they get into the solution. Data were taken from Bulmer and Eccleston (2003) research about photocopier realibility model.

Keywords : Weibull distribution, Newton-Raphson, Bisection, parameter, likelihood function

\section{PENDAHULUAN}

Berdasarkan Ross (1976), distribusi Weibull merupakan distribusi yang banyak digunakan dalam praktek mekanika atau permesinan. Hal ini disebabkan kesesuaian sifatnya terhadap berbagai permasalahan bidang tersebut (versatility). Secara khusus, distribusi Weibull terkait erat dengan pemodelan kekuatan bahan, waktu rusak komponen, peralatan, serta sistem elektronik dan mekanik. Stone dan Heeswijk (1977) memodelkan distribusi kerusakan komponen elektronika berdasarkan distribusi Weibull. Bulmer dan Eccleston [1] juga telah memodelkan keandalan mesin fotokopi menggunakan beragam model distribusi Weibull.

Pemodelan distribusi masa hidup tentu melibatkan fungsi padat peluang, fungsi distribusi, fungsi ketahanan, fungsi laju kerusakan dan fungsi karakteristik lainnya. Fungsi-fungsi tersebut tak lain merupakan fungsi parameter. Oleh karena itu, pengetahuan mengenai estimasi parameter distribusi selalu menjadi bagian penting pada permasalahan pemodelan distribusi masa hidup suatu objek. Adapun Metode estimasi yang sering digunakan antara lain adalah estimasi persekitaran maksimum (MLE), metode estimasi kuadrat terkecil (least square), dan metode estimasi Bayesian.

Pada kasus distribusi Weibull univariat, Stone dan Heeswijk (1977) menguraikan estimasi parameter Weibull 3 parameter dengan menggunakan metode grafik dan $M L E$ untuk data tersensor. Estimasi ini digunakan untuk model distribusi kerusakan alat-alat elektronik. Sedangkan Bhattacharya dan Bhattacharjee [2] , 
telah mempelajari estimasi parameter Weibull 2 parameter pada model kecepatan angin yang digunakan untuk tenaga pembangkit listrik. Metode yang digunakan adalah $M L E$ dan Least square. Pada banyak pembahasan mengenai estimasi parameter distribusi Weibull dengan metode persekitaran maksimum, aproksimasi numerik Newton-Raphson seringkali digunakan untuk mendapatkan solusi dari fungsi persekitaran. Hal ini wajar, dikarenakan oleh ketiadaan solusi analitis atau tertutup dari fungsi persekitaran distribusi Weibull.

Makalah ini meninjau kembali permasalahan estimasi persekitaran maksimum untuk parameter Weibull dua parameter dengan mengujicobakan metode aproksimasi numerik lainnya, yaitu belah dua (biseksi). Selain itu, metode Newton-Raphson tetap disajikan untuk kemudian dibandingkan akurasi dan kecepatannya dalam menemukan solusi.

\section{DISTRIBUSI WEIBULL DUA PARAMETER DAN ESTIMASI PERSEKITARAN MAKSIMUMNYA}

Suatu variabel acak kontinu non-negatif $X$, dikatakan memiliki distribusi Weibull dua parameter ditulis sebagai $X \sim \operatorname{Weibull}(\alpha, \beta)$ dengan $\alpha>0$ dan $\beta>0$, apabila memiliki fungsi padat peluang yang memenuhi persamaan berikut

$$
f(x ; \alpha, \beta)=\frac{\beta}{\alpha^{\beta}} x^{\beta-1} \cdot e^{\frac{1}{\alpha^{\beta}} x^{\beta}}
$$

$\alpha$ merupakan parameter skala yang menunjukkan karakteristik hidup distribusi Weibull. Sedangkan $\beta$ merupakan parameter bentuk yang menunjukkan ukuran penyebaran data waktu hidup. Semakin besar nilai $\beta$, grafik fungsi padat peluang akan melandai, demikian pula sebaliknya.

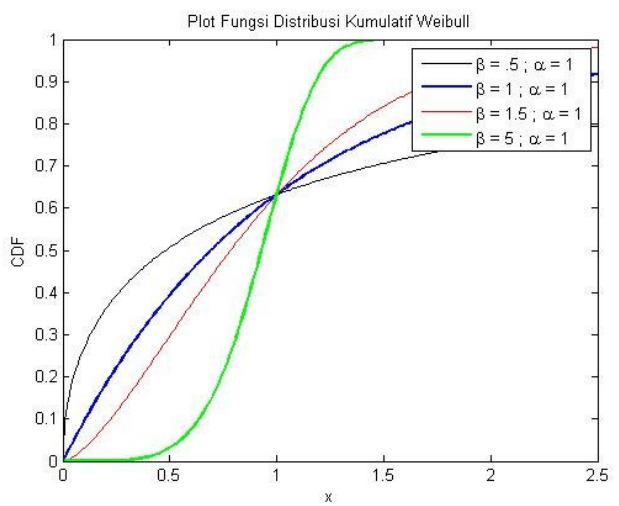

Gambar 1. Plot Fungsi Distribusi Kumulatif Weibull Dua Parameter

Misalkan $X$ dipandang sebagai peubah acak yang merepresentasikan masa hidup atau waktu antar kerusakan suatu objek, fungsi padat peluang dapat diartikan sebagai peluang objek tersebut bertahan selama $x$. Artinya, jika dituliskan $f(25)$, fungsi ini menunjukan nilai peluang suatu objek dapat hidup selama 25 satuan waktu (detik, menit, jam, hari, bulan, tahun, dst). Dalam hal ini, nilai $\alpha$ menunjukkan bahwa $63,212 \%$ masa hidup objek berada pada nilai $x=a$.

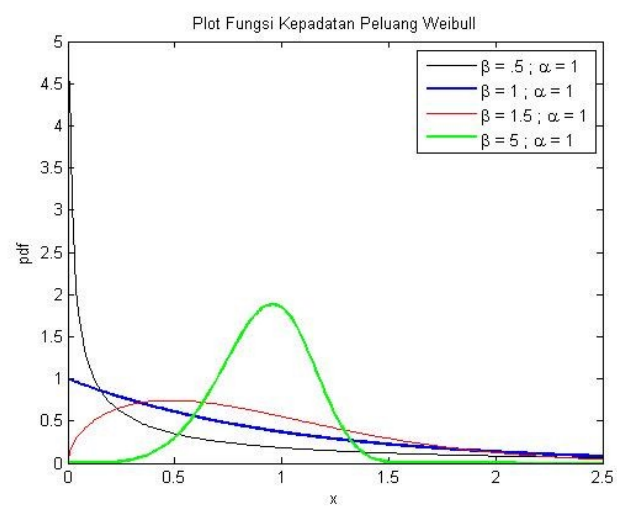

Gambar 2. Plot Fungsi Padat Peluang Distribusi Weibull Dua Parameter.

Kesimpulan ini dapat diperoleh apabila dilakukan pengamatan terhadap fungsi distribusi kumulatif Weibull, yang tak lain merupakan integrasi persamaan (1), yaitu

$$
F(x)=1-e^{-\frac{1}{\alpha \beta} x^{\beta}}
$$

Pada nilai $x=\alpha=1, F(\alpha)$ akan selalu mencapai nilai $1-e^{-1}=0.63212$. Visualisasi peranan parameter $\alpha$ dan $\beta$ dapat diamati masingmasing pada plot fungsi distribusi kumulatif dan fungsi padat peluang di gambar 1 dan gambar 2 .

Estimasi persekitaran maksimum diawali dengan mengkonstruksi fungsi persekitaran Weibull. Fungsi inilah yang nantinya akan dimaksimasi, dengan mencari nilai maksimum dari $\hat{\alpha}$ dan $\hat{\beta}$. Konstruksi fungsi persekitaran didasarkan pada fungsi padat peluang di persamaan 1. Misalkan $X_{1}, \ldots, X_{n}$ merupakan peubah acak yang berdistribusi identik dan independen dengan fungsi kepadatan peluang $f(x ; \alpha, \beta)$. Fungsi persekitaran Weibull diberikan oleh

$$
\begin{aligned}
L\left(\alpha, \beta ; x_{i}\right) & =\prod_{i=1}^{n} f\left(\alpha, \beta ; x_{i}\right) \\
& =\prod_{i=1}^{n} \frac{\beta}{\alpha}\left(\frac{x_{i}}{\alpha}\right)^{\beta-1} \cdot e^{-\left(\frac{x_{i}}{\alpha}\right)^{\beta}}
\end{aligned}
$$

Persamaan 3 perlu ditransformasi supaya dapat lebih representatif untuk proses selanjutnya. Perhatikan bahwa terdapat komponen eksponensial pada persamaan 3 . 
Dengan demikian, transformasi yang tepat adalah transformasi logaritma, sehingga diperoleh fungsi logaritma persekitaran berikut :

$$
\begin{aligned}
l(\alpha, \beta) & =\ln L\left(\alpha, \beta ; x_{i}\right) \\
& =n \ln \beta-n \beta \ln \alpha \\
& +(\beta-1) \sum_{i=1}^{n} \ln \left(x_{i}\right) \\
& -\frac{1}{\alpha^{\beta}} \sum_{i=1}^{n}\left(x_{i}\right)^{\beta}
\end{aligned}
$$

Nilai maksimum dari $\hat{\alpha}$ dan $\hat{\beta}$ diperoleh dari turunan pertama fungsi logaritma persekitaran, masing-masing terhadap $\alpha$ dan $\beta$. Tentunya, sebelumnya telah dijamin eksistensi dan ketunggalan solusi dari persamaan 4 sebagaimana pada Kinasih [3]. Berikut merupakan turunan pertama fungsi logaritma persekitaran Weibull terhadap masing-masing parameternya :

$$
\begin{gathered}
\frac{\partial l(\alpha, \beta)}{\partial \alpha}=-n \beta\left(\alpha^{\beta+1}\right)+\alpha \beta \sum_{i=1}^{n} x_{i}^{\beta} \\
\frac{\partial l(\alpha, \beta)}{\partial \alpha}=\frac{n}{\beta}-n \ln \alpha+\sum_{i=1}^{n} x_{i}^{\beta} \\
+\frac{\ln \alpha \sum_{i=1}^{n} x_{i}^{\beta}-\sum_{i=1}^{n} x_{i}^{\beta} \ln x_{i}}{\alpha^{\beta}}
\end{gathered}
$$

Perhatikan, nilai kritis untuk persamaan 5a dan 5b tidak dapat diperoleh secara eksplisit. Fakta inilah yang mengakibatkan digunakannya aproksimasi numerik untuk mendapatkan solusi yang diinginkan.

\section{METODE NUMERIK BELAH DUA (BISEKSI) DAN NEWTON-RAPHSON (N-R)}

Pada estimasi parameter distribusi Weibull, aproksimasi numerik sebenarnya digunakan hanya untuk mendapatkan akar atau nilai kritis persamaan 5b. Persamaan 5a dapat dinyatakan sebagai fungsi dari parameter beta, seperti pada persamaan 6. Sehingga ketika telah diperoleh nilai $\hat{\beta}$, maka nilai $\hat{\alpha}$ dapat diperoleh dengan mudah melalui substitusi.

$$
\alpha=\left(\frac{1}{n} \sum_{i=1}^{n} x_{i}^{\beta}\right)^{\frac{1}{\beta}}
$$

Sebelum menerapkan metode aproksimasi numerik belah dua ataupun Newton-Raphson, persamaan 6 terlebih dahulu disubstitusikan pada Persamaan 5b, sehingga didapat fungsi beta seperti pada persamaan 7 .

$$
f(\beta)=\frac{1}{\beta}+\frac{\sum_{i=1}^{n} \ln x_{i}}{n}-\frac{\sum_{i=1}^{n} x_{i}^{\beta} \ln x_{i}}{\sum_{i=1}^{n} x_{i}^{\beta}}
$$

\section{METODE BELAH DUA (BISEKSI)}

Metode numerik biseksi dapat digunakan untuk mendapatkan akar persamaan 7, dimana $\beta \in \mathfrak{R}$. $f$ adalah fungsi kontinu yang terdefinisi di selang $\left[\beta_{1}, \beta_{2}\right]$ dengan $f\left(\beta_{1}\right)>0$ dan $f\left(\beta_{2}\right)<0$, atau sebaliknya. Ide metode biseksi adalah menggunakan interval $\left[\beta_{1}, \beta_{2}\right]$ untuk mengurung akar $f(\beta)$. Sesuai dengan teorema nilai tengah, $f$ pasti memiliki paling tidak satu nilai akar pada interval $\left[\beta_{1}, \beta_{2}\right]$. berikut :

Prinsip kerja metode biseksi adalah sebagai

1. Mendapatkan titik tengah interval $\left[\beta_{1}, \beta_{2}\right]$, yaitu $\beta_{3}=\frac{\left(\beta_{1}+\beta_{2}\right)}{2}$;

2. Jika $f\left(\beta_{3}\right)>0$ maka gantikan $\beta_{1}$ dengan $\beta_{3}$ sehingga interval menjadi $\left[\beta_{3}, \beta_{2}\right]$, lakukan biseksi selanjutnya;

3. Jika $f\left(\beta_{3}\right)<0$ maka gantikan $\beta_{2}$ dengan $\beta_{3}$ sehingga interval menjadi $\left[\beta_{1}, \beta_{3}\right]$, lakukan biseksi selanjutnya;

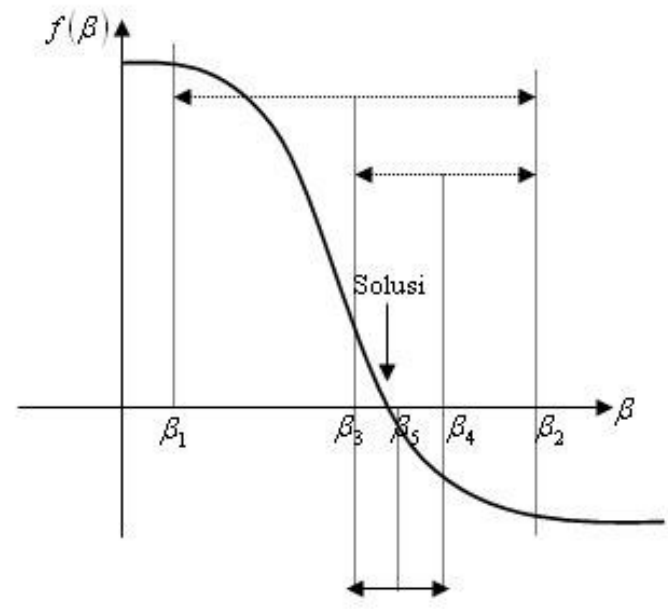

4. Jika $f\left(\beta_{3}\right)=0$, Iterasi dihentikan. Artinya $\beta_{3}$ adalah solusi dari persamaan $f(\beta)=0$ Gambar 3. Ilustrasi Aproksimasi Numerik Belah Dua (Biseksi)

\section{METODE NEWTON-RAPHSON}

Berbeda dengan metode belah dua, Newton-Raphson menggunakan konsep garis singgung fungsi untuk mendapatkan akar suatu persamaan. Idenya adalah memilih satu titik awal untuk dicari nilai fungsinya, kemudian pada nilai fungsi titik awal tersebut dibuatkan suatu garis singgung yang juga memotong sumbu horisontal. Titik potong itulah yang menjadi titik baru, dugaan nilai akar fungsi tersebut. Demikian seterusnya hingga tercapai nilai mutlak selisih 
antar titik yang kurang dari suatu nilai galat yang ditentukan di awal.

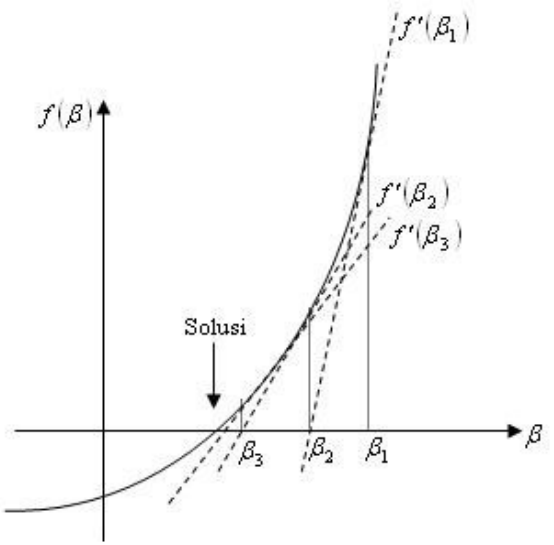

Gambar 4. Ilustrasi Aproksimasi Numerik Newton-Raphson

Karena itu, diperlukan turunan pertama dari persamaan 7 yaitu :

$$
\begin{aligned}
f^{\prime}(\beta) & =-\frac{1}{\beta^{2}}-\frac{\sum_{i=1}^{n} x_{i}^{\beta}\left(\ln x_{i}\right)^{2}}{\sum_{i=1}^{n} x_{i}^{\beta}} \\
& +\frac{\left[\sum_{i=1}^{n} x_{i}^{\beta}\left(\ln x_{i}\right)\right]^{2}}{\left[\sum_{i=1}^{n} x_{i}^{\beta}\right]}
\end{aligned}
$$

untuk dapat menjalankan rumus iteratif Newton-Raphson berikut :

$$
\hat{\beta}_{n+1}=\hat{\beta}_{n}-\frac{f\left(\hat{\beta}_{n}\right)}{f^{\prime}\left(\hat{\beta}_{n}\right)}
$$

Adapun tahapan metode Newton-Raphson dapat disajikan sebagai berikut :

1. Tentukan nilai awal $\hat{\beta}_{n}$. Nilai ini dapat berupa sebarang nilai tebakan, misalkan simpangan baku data;

2. Jalankan iterasi sesuai persamaan 9;

3. Periksa nilai galat yaitu nilai mutlak dari selisih $\hat{\beta}_{n+1}$ dan $\hat{\beta}_{n}$ untuk dibandingkan dengan toleransi galat yang ditentukan, misalkan $e=10^{-5}$.

4. Iterasi dihentikan jika nilai galat telah kurang dari $e$. Artinya, nilai $\hat{\beta}_{n+1}$ itulah yang dijadikan nilai aproksimasi untuk $\hat{\beta}$.

\section{HASIL DAN PEMBAHASAN}

Selain diujicobakan terhadap data kerusakan mesin fotokopi, metode belah dua dan Newton-Raphson terlebih dahulu disimulasikan pada data acak hasil bangkitan beragam ukuran. Hasil simulasi dapat dilihat pada tabel 1.

Selanjutnya, data kerusakan mesin fotokopi berdasarkan waktu kerusakan dan banyak salinan saat kerusakan yang terdistribusi Weibull [1] juga diestimasi menggunakan dua macam aproksimasi numerik ini. Hasilnya dapat dilihat pada tabel 2 .

\begin{tabular}{|c|c|c|c|c|c|c|c|}
\hline \multirow[b]{2}{*}{ No } & \multirow[b]{2}{*}{$\begin{array}{c}\text { Ukuran } \\
\text { Data }\end{array}$} & \multicolumn{3}{|c|}{ Belah Dua } & \multicolumn{3}{|c|}{ Newton-Raphson } \\
\hline & & $\alpha \_h a t$ & $\begin{array}{c}\beta_{-} h \\
\text { at }\end{array}$ & $t$ & $\begin{array}{c}\alpha \_h \\
a t\end{array}$ & $\begin{array}{c}\beta_{-} h \\
a t\end{array}$ & $t$ \\
\hline \multirow{2}{*}{1} & \multirow{2}{*}{10} & 4,820 & 1,5 & 0,0 & 5,22 & 2,0 & 0,20 \\
\hline & & 7 & 20 & 86 & 71 & 49 & 2 \\
\hline \multirow{2}{*}{2} & \multirow{2}{*}{15} & \multirow{2}{*}{5,692} & 1,5 & 0,0 & 4,31 & 1,5 & 0,21 \\
\hline & & & 03 & 92 & 96 & 41 & 6 \\
\hline \multirow{2}{*}{3} & \multirow{2}{*}{30} & 5,360 & 1,6 & 0,1 & 5,43 & 1,7 & 0,34 \\
\hline & & 1 & 81 & 05 & 64 & 71 & 5 \\
\hline \multirow{2}{*}{4} & \multirow{2}{*}{50} & 4,663 & 1,4 & 0,0 & 5,34 & 1,4 & 0,24 \\
\hline & & 3 & 99 & 98 & 65 & 94 & 4 \\
\hline \multirow{2}{*}{5} & \multirow{2}{*}{100} & 5,252 & 1,6 & 0,0 & 5,12 & 1,7 & 0,50 \\
\hline & & 7 & 44 & 90 & 03 & 99 & 5 \\
\hline
\end{tabular}

Tabel 1. Hasil Simulasi Aproksimasi Numerik Belah Dua dan Newton-Raphson

Tabel 2. Hasil Estimasi Parameter Data Waktu dan Banyak Salinan Antar Kerusakan Mesin Fotokopi [1]

\begin{tabular}{ccccccc}
\hline Data & \multicolumn{3}{c}{ Belah Dua } & \multicolumn{4}{c}{ Newton-Raphson } \\
\cline { 2 - 7 } $\begin{array}{c}\text { Fotoko } \\
\text { pi }\end{array}$ & $\begin{array}{c}A_{-} h a \\
t\end{array}$ & $\begin{array}{c}\beta_{-} h \\
\text { at }\end{array}$ & $t$ & $\alpha_{-} h a t$ & $\begin{array}{c}\beta_{-} h \\
a t\end{array}$ & $t$ \\
\hline Waktu & & & & & & \\
antar & 47,6 & 1,7 & 0,3 & 47,634 & 1,7 & 0,4 \\
$\begin{array}{c}\text { kerusa } \\
\text { kan }\end{array}$ & 98 & 28 & 9 & & 19 & 6 \\
\hline $\begin{array}{c}\text { Salinan } \\
\text { antar } \\
\text { kerusa } \\
\text { kan }\end{array}$ & $\begin{array}{c}305 \\
69\end{array}$ & 1,2 & 0,3 & 30567, & 1,2 & 0,5 \\
\hline
\end{tabular}

\section{PENUTUP}

Ketiadaan solusi analitis bagi metode estimasi persekitaran distribusi Weibull berakibat pada penggunaan aproksimasi numerik. Makalah ini menggunakan metode numerik belah dua dan Newton-Raphson untuk menemukan estimator parameter bentuk $\hat{\beta}$, untuk selanjutnya mendapatkan estimator parameter skala $\hat{\alpha}$ melalui substitusi.

Dapat diperhatikan bahwa metode belah dua relatif lebih praktis karena algoritma metode ini hanya membutuhkan turunan pertama fungsi persekitaran terhadap beta seperti pada persamaan 7. Sedangkan metode NewtonRaphson masih memerlukan turunan pertama dari persamaan 7 untuk dapat menjalankan algoritmanya.

Hasil simulasi menunjukkan bahwa metode belah dua juga terpantau memiliki waktu eksekusi lebih singkat dan hasil aproksimasi yang relatif lebih mendekati nilai parameter sesungguhnya. Sedangkan, hasil uji coba terhadap data kerusakan fotokopi baik berdasarkan waktu kerusakan dan banyak salinan saat kerusakan menunjukkan hasil aproksimasi numerik kedua metode mendekati 
hasil estimasi Bulmer dan Eccleston [1]. Namun kali ini, metode numerik Newton-Raphson cenderung memiliki hasil yang paling mendekati estimator di penelitian mereka.

\section{REFERENSI}

[1] M. Bulmer and J. Eccleston, Photocopier Reliability Modeling Using Evolutianary Algorithm., John Wiley \& Sons, 2003.

[2] P. Bhattacharya and R. Bhattacharjee, "A Study on Weibull Distribution for Estimating the Parameters," Journal of Applied Quantitative Methods, vol. 2, p. 5, 2010.

[3] I. P. Kinasih, "Penaksiran Parameter Distribusi Weibull Bivariat Menggunakan Algoritma Genetika," Tesis, 2012. 